\title{
Promoting Pre-Service Primary Teachers' Development of NOSI Through Specific Immersion and Reflection
}

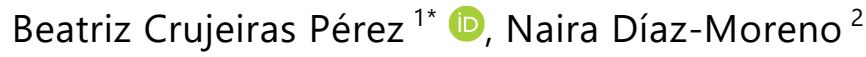 \\ 1 Universidade de Santiago de Compostela, SPAIN \\ 2 Universidad de Murcia, SPAIN
}

Received 15 September 2020 - Accepted 7 December 2021

\begin{abstract}
This study examined pre-service primary teachers' (PPTs) initial NOSI conceptions and their evolution after the immersion in a specific teaching module focused on inquiry and NOSI. The participants were 40 PPTs attending a science education course during a semester. The study consisted of a pre-test/post-test design approach framed qualitative methods. The intervention consisted of nine 90-minute sessions in which participants addressed NOS and NOSI aspects through explicit-reflective teaching combined with the implementation of inquiry tasks set in everyday-life contexts. Data were collected through an open-ended questionnaire both at the beginning and at the end of the module and they were examined through content analysis. The main findings suggest that pre-service teachers presented naive NOSI conceptions when entered the course, and their ideas improved considerably in most of the NOSI aspects after their immersion in the teaching module.
\end{abstract}

Keywords: epistemology, inquiry, NOSI, pre-service teachers

\section{INTRODUCTION}

This study aims to examine the potential of a teaching module about scientific inquiry (SI) and nature of science (NOS) for promoting developing adequate PPTs' nature of scientific inquiry (NOSI) conceptions.

In this study NOSI is understood as the characteristics of the scientific processes through which scientific knowledge developed, accepted, and utilized (Schwartz, 2004). More specifically, it involves individual's understanding about scientific inquiry process, the way of scientific knowledge developed and justified, and what scientists really do (Vhurumuku \& Mokeleche, 2009). It needs to be noted that NOSI is frequently addressed embedded in SI practices, which contributes to confuse both aspects (Lederman \& Lederman, 2014). Hence, there is a need of addressing both terms separately, differentiating between the process of doing science (the practice of SI) and the nature of the operations involved in the process (NOSI).

The relevance of addressing NOSI in science lessons relies on the need of a meaningful engagement in scientific practices (Berland et al., 2016), in this case in the inquiry practice, understood as the characteristic of the scientific processes through which scientific knowledge is developed (Schwartz et al., 2004). According to Osborne (2014), learners need to understand the NOS and NOSI aspects in order to engage in the epistemic knowledge of science. For instance, learners may be able to carry out a scientific investigation, but they need also to understand the nature of the inquiry practices in order to evaluate the validity of scientific claims and understand how scientific knowledge is produced (Schwartz et al., 2012). Therefore, NOSI is essential for performing adequately SI (Lederman et al., 2013). In fact, as Lederman et al. (2014) point out that students' engagement in inquiry do not necessary involves developing their understandings about inquiry. Empirical studies about students' inquiry learning support this statement. For instance, Sandoval and Morrison (2003) explored the effects of an inquiry unit about evolution on students' beliefs about the nature of science, finding that the intervention did not improve students' ideas about inquiry. Similarly, Bell et al. (2003) explored the effect of a science program on secondary students' conceptions about NOS and inquiry, observing that although most students did

(c) 2022 by the authors; licensee Modestum. This article is an open access article distributed under the terms and conditions of the Creative Commons Attribution License (http://creativecommons.org/licenses/by/4.0/). 


\section{Contribution to the literature}

- To gain understanding of how PPTs who are not familiar to inquiry practices change their NOSI conceptions after their immersion in a specific intervention about inquiry practices combined with explicit reflection of NOSI.

- To provide an example of intervention (teaching module) based on immersion in inquiry practices and on explicit reflection of NOSI that can be useful for initial teacher training courses when participants are not familiar with inquiry

- To provide an example of NOSI conceptions analysis based on participants' performances, aligned to qualitative methods, such as content analysis.

appear to gain knowledge about the inquiry performances, their NOSI conceptions remained unchanged.

Moreover, understandings about NOSI are considered as part of scientific literacy (Kampourakis, 2016). In fact, the 2015 PISA framework for assessing scientific competencies includes some of these aspects under the term of epistemic knowledge, such as how measurement error affects the degree of confidence in scientific knowledge or the function of different forms of empirical enquiry in establishing knowledge, their goal (to test explanatory hypotheses or identify patterns) and their design (observation, controlled experiments, and correlational studies) (OECD, 2016).

\section{THEORETICAL FRAMEWORK AND BACKGROUND}

This study is framed in the Epistemology of Science, discipline that addresses the ways in which knowledge claims in science are developed and justified (Ryder \& Leach, 2008), as well as the nature of evidence, criteria for theory choice and the structure of the disciplinary knowledge (Kelly, 2008). This discipline covers several aspects related to the development of scientific knowledge.

In science education, there are several approaches for the teaching and learning the nature of scientific knowledge. Lederman (1992) and Lederman et al. (2013) characterized a set of general aspects of NOS that define the scientific enterprise and that should be taught in science lessons, such as that scientific knowledge is subject to change, it is empirically-based subjective, it necessarily involves human inference, imagination, and creativity, that it is socially and culturally embedded, the distinction between observations and inferences, and the functions of, and relationships between scientific theories and laws. They proposed differentiating between NOS, NOSI, and SI and addressing them separately instead of embedded into SI (Lederman, 2014; Lederman et al., 2014). Other approaches such as Allchin's (2011) emphasizes multiple dimensions aimed at the analysis of reliability or trustworthiness in scientific practice. Moreover, Erduran and Dagher (2014) propose a holistic approach to NOS learning integrating perspectives from Philosophy of Science and Science Education, such as respect for diversity and inclusion, care for motivation and affective dimensions of learning; and social justice in making science and scientific reasoning accessible. García-Carmona and Acevedo (2018) focus on the nature of scientific practice rather on nature of science they propose making learners aware of the meta-knowledge of science while they engage in scientific practices.

In this paper we draw from Lederman $(1992,2014)$ and Lederman et al. (2014) focusing on NOSI aspects. Following this perspective and regarding the NOSI aspects that should be introduced in science lessons, several categorizations have been developed in science education (Lederman et al., 2014; Osborne et al., 2003; Schwartz, 2008). Although these frameworks are different, they articulate some similar key aspects as follows:

1. questions guide scientific investigations;

2. there are multiple scientific methods instead one standard;

3. knowledge claims need to be justified and must be consistent with the data; and

4. distinction between data and evidence.

Nehring (2018) proposed also as NOSI aspects the following:

1. scientists are guided by ideas and plan observations;

2. Scientists change only one variable at a time for valid experiments;

3. Scientists carry out investigations on models; and

4. they test hypotheses about an original object using models.

Although the argument for addressing NOSI in science lessons is well grounded, this topic is not frequently addressed. One reason that can motivate the absence of NOSI in science lessons could be the teaching constraints described in literature, such as the lack of informed views about NOS and NOSI (Capps \& Crawford, 2013), the irrelevance of NOSI for teachers, compared to the other scientific topics they must teach (Strippel \& Sommer, 2015) or the lack of an adequate 
pedagogical content knowledge (PCK) for NOSI (Mesci et al., 2020).

Capps and Crawford (2013) identified not informed views of NOSI in a group of 26 well qualified teachers that were also translated to their lessons. Strippel and Sommer (2015) examined how teachers incorporate learning about SI into laboratory work in the Chemistry classroom, finding that NOSI is not a primary teaching goal for them. Mesci et al. (2020) examined the influencing factors of pre-service science teachers' PCK for NOS and NOSI in a teacher development program, finding an improvement in participants' understanding of NOS and NOSI as well as in their ability to successfully enact the PCK for NOS and NOSI into their teaching practices for middle science.

Another reason can be related to the curricular demands that influence the teaching of science. In Spain, for instance, the current science curriculum for primary education contains specific content knowledge related to scientific activity, such as planning and carrying out single investigations and communicating the obtained findings. However, it does not mention any specific construct of NOSI.

Several approaches to introduce NOS and NOSI into science lessons have been used and examined across the years in research. According to Lederman et al. (2013), they can be classified as the implicit perspective, that suggests that students will learn NOS and NOSI by engaging in hands-on inquiry tasks, the historical approach, which means introducing NOS through history of science, the explicit approach that involves specific instruction about NOS and NOSI in science lessons to improve learners' views, and the explicit reflective approach that involves reflection about NOS and NOSI aspects in specific tasks during science lessons. In this study, we adopt the explicit reflective approach for assessing participants' understandings of NOSI before and after the implementation of a specific unit about SI and NOS. This approach is selected based on the recommendations mentioned before (e.g., Bell et al., 2003; Lederman et al., 2014; Osborne, 2014; Schwartz, 2012), as well as on some recent empirical studies examining NOSI such as Leblebicioglu et al.'s (2017) who examined the potential of an inquiry science camp for promoting NOSI conceptions and finding that explicit reflection about NOSI after each inquiry session was effective for that purpose. Moreover, Erumit et al. (2019) found that reflecting on NOS aspects during contentrelated inquiry activities enhances students' NOSI understandings.

In Spain, there is a broad corpus of research about the teaching and learning of NOS, from theoretical approaches (e.g. Acevedo-Díaz, 2008, 2009; AcevedoDíaz \& García-Carmona, 2016; Vázquez et al., 2004), studies about PPTs' NOS conceptions (e.g. Díaz-Moreno \& Crujeiras-Pérez, 2016; Guisasola \& Morentin, 2007;
Mellado, 1996; Vázquez-Alonso et al., 2014,) or analysis of teaching proposals' potential for improving PPTs' NOS conceptions (e.g. Acevedo-Díaz et al., 2017; Crujeiras-Pérez \& Puig, 2014; Escrivá-Colomar \& RiveroGarcía, 2017; Vázquez-Alonso \& Manassero-Mas, 2016).

Although NOS is widely addressed in Spanish scientific education, NOSI is less studied. In fact, to date we have not identified specific NOSI studies in PPT education, only in secondary education, and those point to a naive view for all NOSI for the $50 \%$ of the students that took part of the study (Lederman et al., 2021) as well as to difficulties for identifying these aspects in real situations (Hamed et al., 2017).

Our research seeks to contribute to fill this gap by examining PPTs' NOSI initial conceptions and their evolution after taking a teaching module about NOS/NOSI and SI.

\section{RESEARCH QUESTIONS}

The specific research questions that guide our investigation are as follows:

1. What NOSI conceptions does a group of present Spanish PPTs when enrolling Science teaching courses?

2. To what extent does a teaching module about SI, NOS and NOSI contributes to develop adequate participants' NOSI conceptions?

\section{METHODOLOGY}

\section{Participants}

The study took place in a public university at the northwest of Spain. The participants were 40 PPTs (10 males and 30 females) attending a science education course during a semester. The PPTs were in the second year of the degree in Primary Education, and this was their first course about science and science education in the study program. Hence, they had no experience in inquiry practices, and at best, only in following preestablished procedures during secondary education. It is worth mentioning that the $65 \%$ of the participants did not study science since they were 16 years old, which is the last year of compulsory education in Spain. This lack of scientific knowledge in participants needs to be compensated in science education lessons by explaining both science and science teaching and learning methods.

\section{Design of the Study}

The study consisted of a pre-test/post-test design approach framed qualitative methods in order to assess the potential of a teaching module about scientific inquiry in primary education. The intervention consisted of nine 90-minute sessions in which participants addressed NOS and NOSI aspects through explicitreflective teaching combined with the implementation of 


\begin{tabular}{|c|}
\hline $\begin{array}{c}\text { 1.Lecture } \\
\text { NOS tenets and } \\
\text { scientific methodology }\end{array}$ \\
\begin{tabular}{|c|} 
2.Workshop \\
Operations involved in \\
planning a scientific \\
investigation
\end{tabular} \\
\hline $\begin{array}{c}\text { 3. Laboratory inquiry } \\
\text { Planning how to check } \\
\text { the effectiveness of a } \\
\text { detergent }\end{array}$ \\
\hline
\end{tabular}

4. Workshop Operations involved in carrying out an investigation and drawing conclusions

5. Laboratory inquiry
Checking the
effectiveness of a
detergent

6. Lecture Inquiry continuum and scientific competency

7. Laboratory inquiry
Planning/ implementing
an investigation to
choose the best paper
towel

\begin{tabular}{c} 
8. Lecture \\
Contexts for promoting \\
NOS, NOSI and SI \\
\hline
\end{tabular}

9. Workshop

Designing a SI task

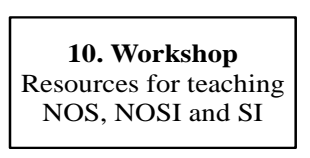

a) PSTS are presented the characteristics of scientific knowledge (e.g. :tentative; based on empirical evidence; socially and culturally embedded, $\vdots \ldots)$ and are required to identify them in several historic examples or daily: life issues. b) PSTs are presented the main operations involved a in scientific investigation and relate them to the NOS tenets

PSTs are presented the cake recipe as analogy for planning an investigation. They have to identify the correspondence between the analogy and the iscientific operations involved in the planning. After that they are required to assess two examples of planning for investigating the most appropriate plastic bag from 4 options. Reflection of NOSI aspects through open questions raised by the teacher is carried out.

PSTs are required to plan an investigation to find out if a detergen announced in the media as the most efficient for removing all types of stains, really works. They are provided with some scaffolding questions for helping PSTs with the planning. After that, ,PSTs have to evaluate all the :plans proposed by the classroom and reflect on their feasibility, accuracy :and reliability, reproducibility

PSTs are explained the operations related to carrying out an investigation :(observation, measurement, data collection), the interpretation of results and drawing conclusions. Aspects related to the accuracy of measures, relevance of identifying anomalous results, the need of finding patterns in data and drawing evidence-based conclusions are introduced through examples.

PSTs carry out the designed investigation and draw a conclusion. After that :they are required to reflect on the findings in terms of reliability and accuracy. Teacher open questions related to these aspects and NOSI are :prompted. To conclude, the PSTs have to write a report defending their conclusion

PSTs are introduced to the inquiry continuum and a required to classify several examples of inquiry experiences. After that inquiry is related to scientific competencies and PSTs have to identify the best examples to :enable scientific competency through inquiry

PSTs are provided with an incomplete example of procedure that they have :to assess in terms of accuracy, reliability, feasibility, replicability and systematicity. After that they have to complete the procedure, share their :proposals with the other small groups and carry out the experiment for :drawing a conclusion. Teacher open questions related to NOSI reflections are prompted.

PSTS are provided with examples of context that enable the learning of NOS, NOSI and SI and they have to discuss the NOS and NOSI aspects involved in each example as well as the inquiry skills.

PSTs are introduced into the design of learning environments for SI, NOS and NOSI. They are required to design a task for teaching a particular scientific content through inquiry. They have to include the NOS and NOSI aspects to be promoted in their proposal

PSTs are introduced to the lapbook as a learning resource, and they are asked to design a specific lapbook for addressing a particular content knowledge through SI in primary education. They have to include NOS and NOSI aspects.
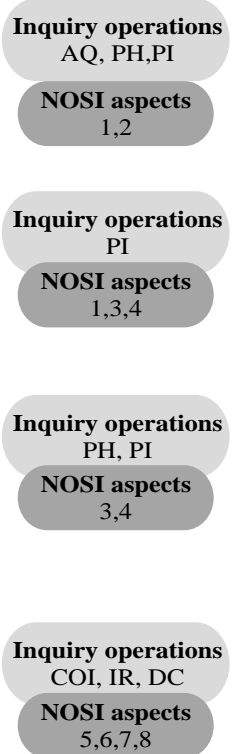

$5,6,7,8$
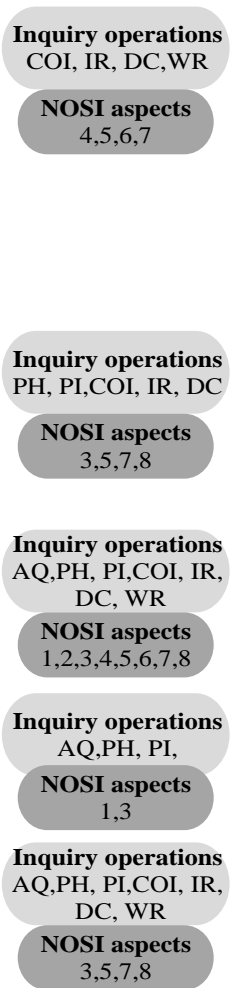

Figure 1. Description of the inquiry and NOSI intervention. NOSI aspects: 1-Scientific investigations all begin with a question; 2-The process of investigation is regressive rather than a lineal set of steps or operations; 3-A scientific design must be detailed, accurate, feasible, reliable, and reproducible; 4-Inquiry procedures can influence results; 5-Outcome of a single experiment is rarely sufficient to establish a knowledge claim; 6-Recognition of anomalous data; 7-Justification of knowledge claims; 8-Research conclusions must be consistent with the data collected. Inquiry operations: AQ-asking questions; PH-posing hypotheses; PI-planning the investigation; COI-carrying out the investigation; IR-interpreting results; DC-drawing conclusions; WR-writing reports

inquiry tasks set in everyday-life contexts followed by reflection about NOS and NOSI and also about how to implement these aspects in primary lessons. The intervention is summarized in Figure 1.
The NOSI aspects used in this research draw mainly from literature but have also added two more aspects. All of them are reproduced as follows:

1. Scientific investigations all begin with a question (Lederman et al., 2014). 
Table 1. Description of the items that participants responded in the pre- and post-test

\begin{tabular}{lllc}
\hline Question & Type & Description & NOSI aspects addressed \\
\hline 1 & $\begin{array}{l}\text { Multiple choice } \\
\text { Open ended } \\
\text { Open ended }\end{array}$ & $\begin{array}{l}\text { To select the best scheme for carrying out a scientific inquiry } \\
\text { adequate for identifying micro-plastics in beach sand and } \\
\text { obtaining reliable results } \\
\text { To identify reliability criteria in a research conducted by high } \\
\text { school students to find out which material would be the most } \\
\text { adequate for building a race-track for toy cars }\end{array}$ & 3 \\
4 & Open ended & $\begin{array}{l}\text { To select the best conclusion of an investigation about the effect of } \\
\text { Open ended } \\
\text { temperature on the dissolution rate of cocoa in water according to } \\
\text { empirical data and to justify the selection }\end{array}$ & 8,5 \\
\hline
\end{tabular}

2. The process of investigation is regressive rather than a lineal set of steps or operations (proposed by the authors).

3. A scientific design must be detailed, accurate, feasible, reliable, and reproducible (proposed by the authors).

4. Inquiry procedures can influence results (Lederman et al., 2014).

5. Outcome of a single experiment is rarely sufficient to establish a knowledge claim (Osborne et al., 2003).

6. Recognition of anomalous data (Schwartz et al., 2008).

7. Justification of knowledge claims (Schwartz et al., 2008).

8. Research conclusions must be consistent with the data collected (Lederman et al., 2014).

\section{Data Collection}

Data were collected through an open-ended questionnaire both at the beginning and at the end of the module. The questionnaire was developed by the authors and shared with two external experts who were asked to complete it and to analyze the writing in terms of understanding. Then it was used in a pilot study with PSTs in order to examine if their responses would represent what the authors were investigating in the NOSI study. Some little writing adaptations were made after the pilot study and before being used in the current research. The final version of the questionnaire, reproduced in the appendix, consisted of four questions that combined multiple choice items with open ended questions. The description of the items is summarized in Table 1.

\section{Data Analysis}

The data were examined through content analysis (Schreirer, 2012), which enables a systematic description of context-dependent meaning of data. To this aim, participants' responses to each question were analyzed separately and inductively coded using ATLAS.ti

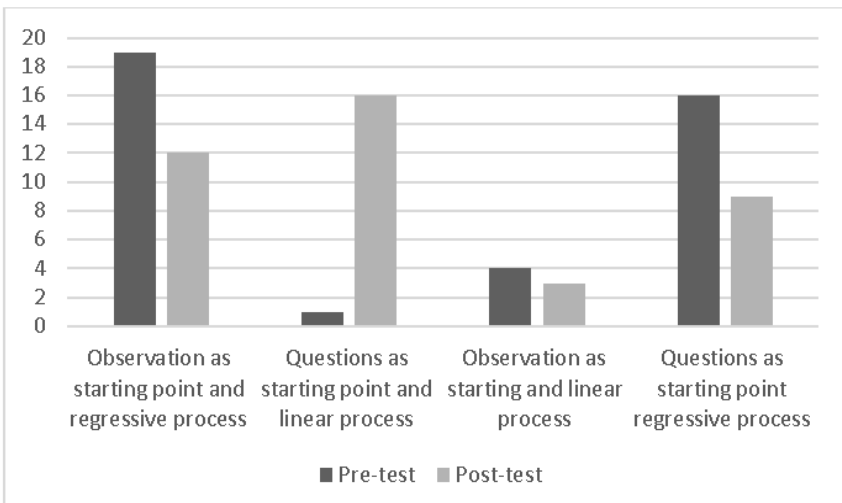

Figure 2. Options selected by participants related to the best scheme for carrying out a scientific inquiry

software. The coding was carried out independently for the pre and the post-test through several iterative cycles between both researchers and after that the final rubrics for each question were developed. These rubrics are presented together with the results in the following sections.

To check inter-rater reliability, both researchers coded independently all PPTs' responses, and the results were checked for agreement, obtaining an $85 \%$ of agreement, meaning a reliability coefficient of 0.85 , which is considered as acceptable in qualitative content analysis (Julien, 2008). The remaining 15\% was revised and discussed between the two authors until obtaining a $100 \%$ of agreement.

\section{RESULTS}

The results obtained in the pre and post-test are presented separately for each NOSI aspect and discussed according to each research question.

\section{Pre-Service Teachers' Initial NOSI Conceptions}

\section{Scientific investigations all begin with a question}

This aspect is examined through participants' responses to item 1 , which required selecting the best scheme for carrying out a scientific inquiry from four options. Figure 2 summarizes the findings. 


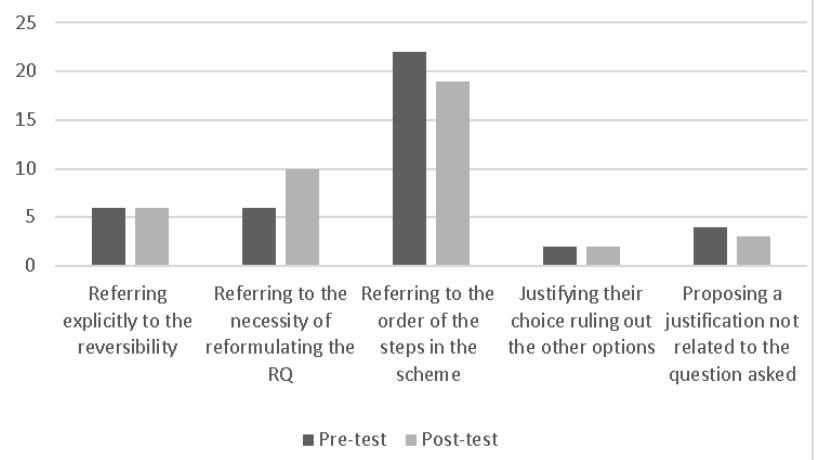

Figure 3. PSTs' justifications in relation to the most adequate scheme for representing general steps of a scientific inquiry

The data represented in Figure 2 reveal that 23 out of 40 participants considered observation (options a and $c$ in the test) as starting point for obtaining new scientific knowledge, whereas 17 acknowledged that new knowledge emerges from questions (options b and $d$ ). This means that $57 \%$ of the pre-service teachers entered the course with a naive view of how knowledge is developed in science.

\section{The process of investigation is regressive rather than a lineal set of steps or operations}

This aspect is examined through participants' justifications to their selections in item 1 and the results are summarized in Figure 3.

Examining participants' responses to each option, only 16 out of 40 selected the adequate option (option d), which represents a non-lineal process. The most frequent choice corresponded to option a, selected by 19 out of 40 participants which is only regressive once the conclusions are obtained. The rest of the options, $b$ and $\mathrm{c}$, intermediate between a and $\mathrm{d}$, were selected by very few participants (one and four, respectively).

As described in Figure 3, most frequent justification was related to the order in which the operations involved in the process should be carried out, being mentioned by 22 out of 40 participants. The other four categories identified were less frequent, being only six participants those who referred explicitly to the reversibility of the operations, whereas other six considered implicitly this aspect, proposing the need of reformulating the research if the results were not the desired. In general, only $30 \%$ of participants acknowledged the non-linear character of scientific processes.

\section{A scientific design must be detailed, accurate, feasible, reliable, and reproducible}

This aspect is assessed in the item 2, in which participants must justify which procedure (from two options) would be the most adequate for identifying

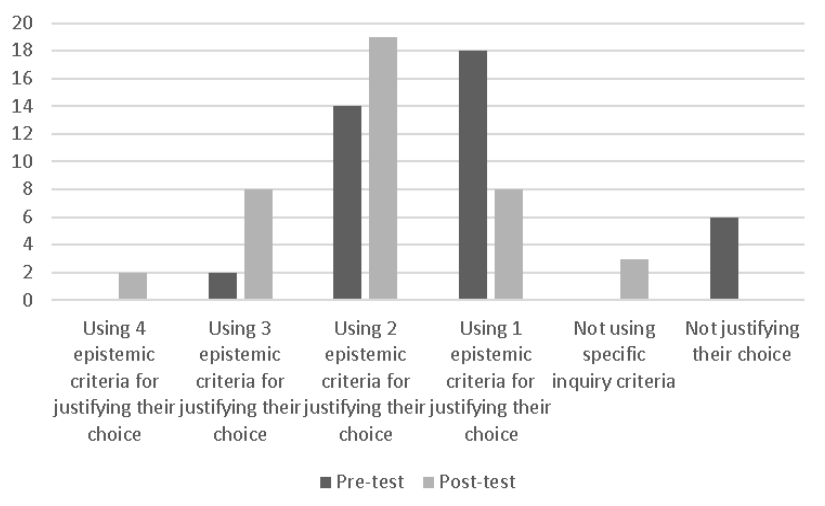

Figure 4. Criteria applied for selecting the most adequate scientific procedure

micro-plastics in beach sand and obtaining reliable results. The analysis has been conducted in terms of epistemic criteria. By epistemic criteria we refer to the standards that scientists use to evaluate the validity and accuracy of scientific products (Pluta et al., 2011), being in this case the abovementioned aspects that a scientific design should meet. It needs to be noted that the criteria identified in participants' justifications are the detail, order, reproducibility, reliability, and accuracy. The findings are summarized in Figure 4.

The findings point to the use of one or two epistemic criteria in participants' justifications for selecting the best scientific procedure, being identified in 18 and 14 preservice teachers respectively, which represented the $80 \%$ of the participants. Only two included more than two epistemic criteria in their justifications.

Moreover, there were six participants that did not justify their choice, perhaps due to the lack of knowledge about NOSI for making their choice.

\section{Inquiry procedures can influence results}

This aspect is assessed in item 3 in terms of reliability. The participants had to decide whether a procedure conducted in research to find out which material would be the most adequate for building a racetrack for toy cars was reliable or not and justifying their decision. Participants' justifications are examined in terms of the aspects involved in the design of the procedure that they associate to reliability. The results are described in Figure 5 and Figure 6.

In this case, 26 participants $(65 \%$ of the total) identified the process as not reliable, which corresponds to the expected answer. However, there were 13 participants that recognized the process as reliable and one that did not provide any answer, as described in Figure 5 .

As reported in Figure 6, 27 out of 40 participants related reliability with a particular aspect involved in the design of the procedure, which means that this aspect influences results. There was a wide range of aspects that 


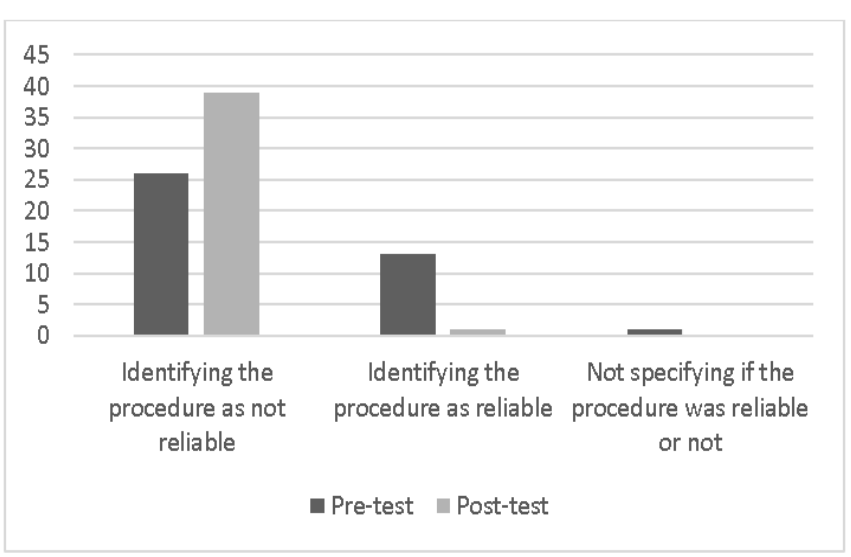

Figure 5. PSTs' identification of reliability in the process

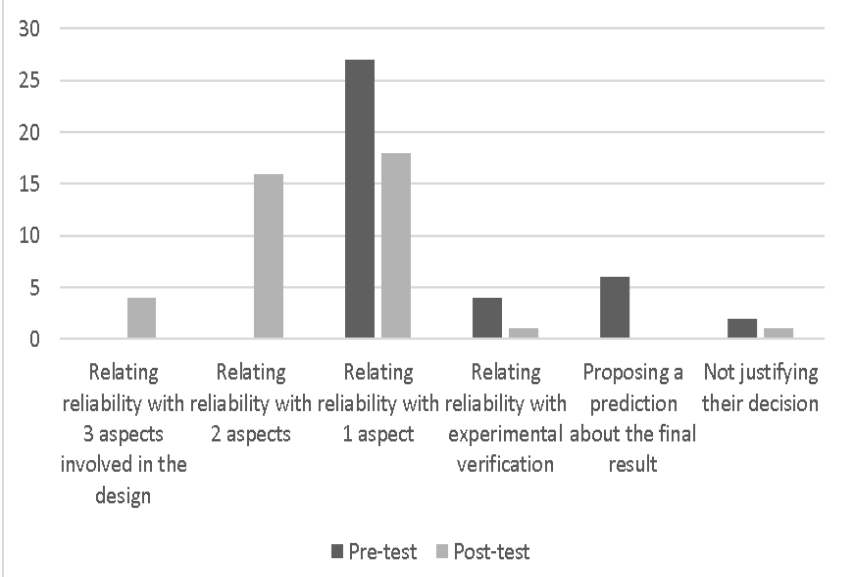

Figure 6. PSTs' justifications about how the procedure influences the results

participants considered as influencing results in terms of reliability, such as controlling other external variables $(\mathrm{N}=14)$, fair testing $(\mathrm{N}=6)$, conducting several tests to ensure results $(\mathrm{N}=6)$, testing all the available materials for building the racetrack $(\mathrm{N}=1)$ or explaining the procedure in-depth $(\mathrm{N}=1)$. Although the aspects identified are varied, the participants only considered one of them in their proposals.

\section{Outcome of a single experiment is rarely sufficient to establish a knowledge claim}

This aspect is also assessed in item 3, examining the consideration of repetitions or of conducting several tests in the criteria that participants propose in their justifications. Considering the results represented in figure 6 , and, examining those related to the category "relating reliability with one aspect involved in the design of the procedure", only six out of the 28 participants acknowledged the need of repeating the experiments in order to obtain reliable results.

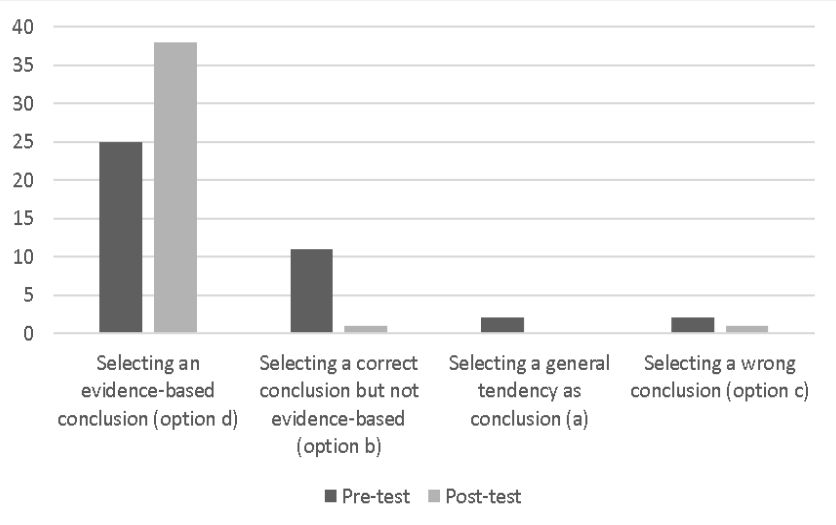

Figure 7. Options selected by PSTS related to the best conclusion for a scientific inquiry

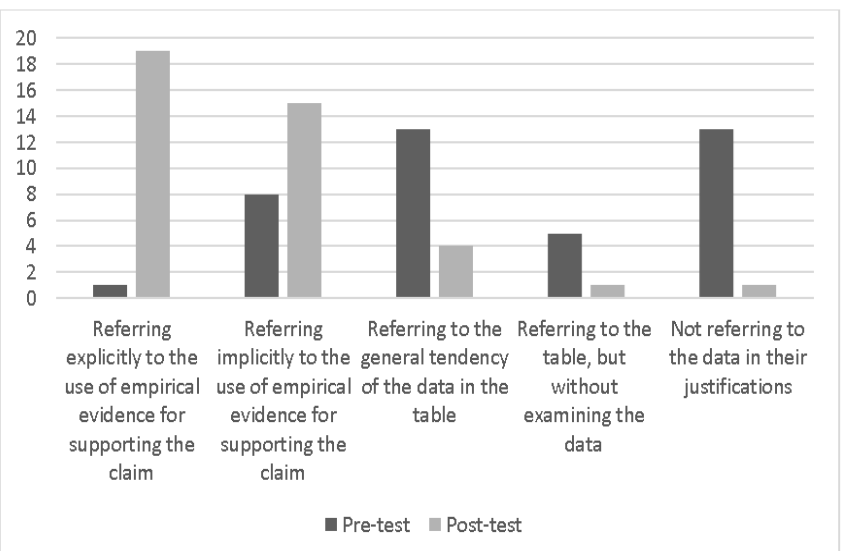

Figure 8. PSTs' justifications to selection of best conclusion

\section{Research conclusions must be consistent with the data collected}

This aspect is assessed in item 4 in which participants had to select the best conclusion in an investigation about the effect of temperature on the dissolution rate of cocoa in water according to empirical data and after that they had to justify their selection.

The abovementioned NOSI aspect is examined in participants' justifications in terms of recognizing the need of supporting claims with evidence, in this case the data collected that were reported in Appendix A. The results are summarized in Figure 7 and Figure 8.

The results reported in Figure 7 point out that more than half of participants selected an evidence-based conclusion (25 out of 40), however their justifications (described in Figure 8) were not as adequate as desired, since only nine of them referred to the empirical data.

Moreover, although 13 participants considered the data for drawing a conclusion, they referred only to the general tendency, without examining them in detail. Other 13 out of the 40 participants did not consider the data for selecting the most adequate conclusion and five of them mentioned the table but they did not examine the data for drawing the conclusion. 
In short, participants' initial NOSI conceptions were naiver than informed, since the $57 \%$ considered that observations are the starting point for developing scientific knowledge instead of questions. $70 \%$ of preservice teachers did not recognize the reversibility of scientific procedures and relate reliability with only one specific aspect of the design. Moreover, $45 \%$ of participants used only one criterion for selecting the most adequate scientific procedure and $85 \%$ of them did not recognize the need of repeating the experiments for ensuring the reliability of results. And finally, $78 \%$ did not recognize the need of supporting scientific claims with specific evidence. Therefore, these results suggest a need of specific training about NOSI.

\section{Evolution of Participants' NOSI Conceptions after Engaging in a Teaching Module on Inquiry and NOS}

Evolution of participants' NOSI conceptions is examined two months after engaging in the teaching module summarized in Figure 1. The findings are discussed in terms of each NOSI aspect comparing the data in the pre-test and post-test.

\section{Scientific investigations all begin with a question}

In general, there is a certain improvement about this aspect, since there is a clear decrease in the number of participants that consider observation as starting point in a scientific process, being 23 in the pre-test and 15 in the post-test.

\section{The process of investigation is regressive rather than a lineal set of steps or operations}

As negative aspect, there was a clear decrease in the acknowledgement of the process as regressive. It is particularly surprising that the $40 \%$ of participants (16 out of 40) still considered the process as linear (see Figure 2), despite having conducted several investigations in the module. This issue can be explained through their justifications to the selected option, summarized in Figure 3.

In general, there were not significant differences in participants' justifications in terms of frequency between the pre and the post-test, being $\mathrm{c}$ the most frequent category, in which participants referred to the order of the steps in the scheme. Regarding the small differences, there was a little increase in the number of participants that justified their choice basing on the need of reformulating the investigation once it was finished (rising from six to 10). Furthermore, there was a decrease in the number of participants that justified their choice with the order of the steps provided in the schemes (from 22 to 19).

It is worth mentioning that all participants justified their choice both in the pre and in the post test, which could be interpreted as a sign of engagement with the task.
Examining the results in terms of single participants, wide differences were identified, especially in relation to the most adequate justification, that was referring explicitly to the reversibility of the operations involved in scientific inquiry. In this case, although the absolute frequency is the same in both tests $(\mathrm{N}=6)$, only two participants provide the same justification. This means that there were four participants that improved their conceptions and, unfortunately, other four went worse. This worsening could be due to the application of their knowledge thinking about the viability of the processes to be performed in primary science lessons instead of applying their knowledge about NOSI. One example of this finding is identified in participant PST 23, who in the pre-test selects the adequate option and provides an adequate justification to this choice, however in the posttest centers their choice in the feasibility of the processes for primary education.

"Carrying out scientific research involves following a pre-established procedure but providing continuous feedback. This means that once the investigation is designed according to a hypothesis and we want to put it into practice (experimentation), something might go wrong, so we would have to go back in order to identify what went wrong and see how to fix it. The same happens if the experimentation provides adequate results but when we interpret them or draw conclusions, they are not the expected, so we have to reformulate the hypothesis or even the design" PST23 (pre-test).

"The students have to learn to pose questions from their own observations in order to formulate a hypothesis that suggest provisional explanations, that explain observations our relations or to make predictions in relation to a principle or concept and to apply knowledge for explaining the phenomena. After that, they have to plan the investigation for identifying what they want to measure, compare or to select the circumstances for observing. Then they must consider how to use those measures, comparisons, or observations for solving the problem. After that, they carry out the investigation selecting the relevant from the irrelevant, identifying both the similarities and the differences, as well as little details, using purposeful observation and not only their senses. The next step will be the data collection and their interpretation, assessing their usefulness, identifying the valid data from the whole group of collected data and selecting the most adequate ones for answering the question. Finally, they will draw conclusions and compare the initial ideas with the evidence" PST23 (posttest). 
In this case, in the post-test the participant justifies their selection according to how she will apply the steps of scientific research in the lessons, which leads her to discard option $\mathrm{d}$ for considering it difficult for primary students and therefore to not acknowledging the reversibility of the steps.

\section{A scientific design must be detailed, accurate, feasible, reliable, and reproducible}

Regarding this aspect, there are relevant differences in participants' responses in terms of type and number of criteria used between the tests, as summarized in Figure 4 . The use of more than one epistemic criterion represents the $40 \%$ of the responses whereas in the posttest it increases to $72 \%$. Moreover, in the post-test, PSTs were able to use up to four epistemic criteria for selecting the most adequate procedure, whereas in the pre-test the maximum is two criteria.

One example of this evolution is represented in the participant PST16, who in the pre-test only considers the level of detail in the procedure whereas in the post-test he uses three criteria (accuracy, level of detail, and reliability).

"[option] A, the procedure to carry out is more detailed, the explanation is therefore more comprehensible, and it will be easy to conduct the process of identifying micro-plastics due to the specification of the steps and quantities" PST16 (pre-test).

"I would choose procedure B because it offers more accurate data for the variables mass and time, it provides all the steps to follow, and it is more reliable because it uses two samples for each type of beach sand and pictures of the observed data. It explains what each equipment is used for and it also makes use of a more scientific vocabulary (for instance, to filtrate instead of to remove). Because of all this I consider that it [procedure b] is more adequate" PST16 (post-test).

Another difference between the pre and the post-test is related to the lack of justifications in participants' responses, which has been only identified in the pre-test $(\mathrm{N}=6)$. However, in the post-test, although all participants provided justifications, not all of them were adequate, based on specific epistemic criteria, since there are three PSTs that did not base their justifications on these criteria but on the adequacy of the content knowledge addressed in the inquiry task, such as the type of mixture composed by the sand and the microplastics (homogeneous or heterogeneous) or the adequacy of the separation technique selected. One example of this category is PST1's response:

"I would consider the type of mixture and their components, the separation procedures or techniques used, checking if they are appropriate for the mixture and if they are correctly carried out. I would also take into account the laboratory materials used for the separation. In this case I would choose the second procedure because in it the suspended particles are collected in a paper filter, the filter is washed with distilled water, and it is dried before observing the micro-plastics with the magnifying glass."

\section{Inquiry procedures can influence results}

In this item, differences between the tests are also observed, since in the pre-test 26 participants identify the process as not reliable whereas in the post-test 39 (out of 40 participants).

Regarding participants' justifications, better results are identified in the post-test than in the pre-test, as reported in Figure 6. In the pre-test, at best, 27 out of 40 participants associate reliability with one aspect involved in the design of the investigation, such as fair testing, repeating the experiments, a detail explanation of the procedure and so on. However, in the post-test 16 participants associate reliability with two aspects and even four PSTs are able to relate it with three different aspects. One example of this finding is the one provided by PST4, who relates reliability with a detailed explanation of the procedure, fair testing and repeating each test:

\footnotetext{
"The obtained results are not reliable because they do not detail the used procedure for carrying out this experiment, asserting that cork is the material that enables the toy car to move faster without providing evidence, such as timing the test with the three materials. Moreover, they do not indicate the number of repetitions carried out and an experiment need to be repeated more than once in order to be reliable. Finally, they did not consider either fair testing or data collection."
}

In addition, in the post-test participants do not base their justifications on their own hypotheses about the final result, as in the pre-test, in which six PSTs did it, maybe due to their lack of knowledge and experience with scientific inquiry. One example is PST21, who in the pre-test pointed the following:

"I think that the findings are not reliable because the cork is in my opinion a material that makes the toy car grip more, so it does not enable it to move faster."

In contrast, in the post-test, this participant is able to relate reliability with two inquiry aspects such as repeating each test and fair testing:

"With the provided information is not possible to know if the results are reliable because they do not 
mention the time that takes the car to reach the finish line. In addition, they do not explain that friction force varies with each material. Moreover, the force exerted for throwing the toy car across the inclined plane may vary, so it would be better to conduct several tests and to write down all data in a table and calculate the averages in order to obtain a more reliable result."

\section{Outcome of a single experiment is rarely sufficient to establish a knowledge claim}

Regarding this aspect, there is a significant improvement in the post-test compared to the pre-test, since 24 participants consider the need of doing several measures with each material assessed, which means an increase of 18 participants, and it represents the $60 \%$ of the pre-service teachers.

It needs to be noted that in the post-test the need of repeating the measures is mainly proposed together with other aspects, such as the detailed explanation of the procedure, the fair testing or controlling additional variables not considered in the initial procedure. One example of the evolution is PST11's proposals, who in the pre-test mentioned only the need of repetition, whereas in the post-test he associates reliability to fair testing and to controlling additional variables.

"I think that the results should be checked more than once, since there could have been a disturbing variable that influenced the results" PST11 (pre-test).

"The obtained results are not reliable because the test should be repeated more than once. This research details the variable that must be kept constant (inclined plane) and the variables that will change as well as the different cars made of different materials. Therefore, the results should be repeated more than once to check the reliability of the test and to avoid the influence of disturbing variables, such as an increase in heat, a failure in the execution of the process, the wind if it is conducted outdoors ... All which is not controlled in the research can modify the result, hence the importance of deciding how many times to perform (repeat) the test" PST11 (post-test).

\section{Research conclusions must be consistent with the data collected}

Concerning this aspect, a high number of participants select an evidence-based conclusion in the pre-test $(\mathrm{N}=25)$, but this proportion increases considerably in the post test (38 out of 40). About the justifications provided for the selection of the most appropriate conclusion, there are important differences between the pre and the post-test, as shown in Figure 8. Thus, in the pre-test only 9 out of 40 participants consider the need of supporting the conclusion with evidence, in this case empirical. On the contrary, in the post-test there are 34 participants who consider this aspect. Likewise, only one participant makes explicit reference to the use of evidence in the pretest, while there are 19 in the post-test. Although both types of justifications are correct, we consider important to differentiate between explicit and implicit. The difference between an explicit reference to the use of tests and an implicit one is illustrated in the responses of participants PST11 and PST6, respectively.

\begin{abstract}
"The most scientifically appropriate conclusion would be D. A conclusion of an investigation consists in answering the question investigated. It must always be justified on the basis of evidence, data or information confirming the conclusion. Cocoa dissolves faster in hot water, since according to the results of the table, as the temperature increases the time it takes to dissolve is less. The temperature and the rate of dissolution are directly related. For example, in the 3 tests performed at $100^{\circ}$, it takes about 30 s $(32,30$, and 31 ) and as the temperature decreases the dissolution time increases. With $65^{\circ}$ it takes about twice as long (60s), with $40^{\circ}$ it is around 100 if with $20^{\circ}$ it exceeds two minutes (121 if 123s) in two of the three. As the temperature increases, the time it takes to dissolve is shorter" PST11 (post-test).

"I think option $\mathrm{d}$ is the most scientifically appropriate because it justifies and provides a result by relating it to the situations that have been established for research, in this case exemplifying it with temperature degrees" PST6 (post-test).
\end{abstract}

The other tendencies identified regarding this issue are related to justifying their choice according to the general tendency of the data provided in the table, to referring to the table but without mentioning particular data or even to alluding to daily life experiences similar to the one investigated, but all of them are less frequent in the post than in the pre-test, which is a sign of improvement.

As a summary, after the intervention, 63\% of participants considered questions as starting point for developing scientific knowledge, although there was still a $37 \%$ that kept observations as first step for conducting inquiry. However, regarding the regression of the operations, the findings are not as good as desired, since only $40 \%$ of participants recognized this aspect. In relation to the use of epistemic criteria, $73 \%$ of preservice teachers used more than one criterion for assessing the adequacy of a scientific procedure, which represented an increase of $33 \%$ in relation to the pre-test. Moreover, $60 \%$ of participants recognized the need of repeating the tests several times to obtain reliable results and $85 \%$ considered the need of supporting claims with evidence. 


\section{DISCUSSION AND CONCLUSIONS}

This study examined PPTs' initial NOSI conceptions and the potential of a teaching module about inquiry and NOSI for improving participants' conceptions. Addressing NOSI in pre-service science teacher education is relevant and necessary for ensuring an adequate enactment of inquiry in science lessons addressed in schools. This assertion is motivated by teachers' difficulties for understanding scientific inquiry (Senler, 2015) and by the lack of relevance that NOSI entails for teachers (Stripple \& Sommer, 2015).

The main findings suggest that PPTs presented naive NOSI conceptions when entered the course, which required a specific training. It should be noted that most participants did not recognise the reversibility of scientific procedures, neither the need of repeating the experiments for ensuring reliability nor the need of supporting claims with specific evidence. Some of these findings are aligned to those obtained in secondary education in our context, which highlight for instance that the $65 \%$ of the students did not recognise that a scientific investigation begins with a question or that the $47.8 \%$ presented a naive view (Hamed et al., 2017). However, some of our findings are opposite to those obtained in other studies, such as Yang et al.'s (2017) who found that high school students did well understand that conclusions must be consistent with data; or Senler's (2015) who identified informed views of students regarding the aspect "scientific investigations all begging with a question". It is worth mentioning that Senler's (2015) study compared students' conceptions about scientific inquiry in two countries (USA and Turkey) obtaining notably differences between the two countries, being USA students' conceptions more informed. The author related this finding to the difference in curricula and hence in scientific education, being the USA curriculum inquiry-based since 1996. This assertion can be extrapolated to our study, in which the science curriculum has been mainly content-based until the reform conducted in 2006, which included a block of contents related to scientific activity but without specific references to scientific inquiry and NOSI. So, it is comprehensible that pre-service teachers that studied compulsory scientific education under a content-based paradigm do not present informed views of NOSI.

Participants' lack of scientific training and therefore of scientific inquiry and NOSI can also influence these naive conceptions, since the $65 \%$ of the participants did not study science since they were 16 years old. This assertion does not mean that we relate NOSI conceptions to scientific knowledge, since there are many studies about NOS and the level of scientific knowledge in literature concluding the opposite (e.g., Lederman, 1999; Schwartz \& Lederman, 2008) and which we agree with. However, the fact of not having received any training on
NOSI and inquiry due to their limited years of scientific study influences their naïve conceptions.

Regarding the second research question, the intervention showed potential for developing NOSI conceptions since students' ideas improved considerably in most of the aspects, although not as much as desired in some cases. For instance, there still was a $37 \%$ of pre-service teachers that in the post-test considered that scientific investigations begging with an observation instead of questions. This finding disagrees with other studies such as Leblebicioglu et al.'s (2017) who observed higher developments in students' conceptions about this aspect after engaging in a science camp that addressed scientific inquiry and explicit NOSI. It needs to be noted that the participants in this study were $6^{\text {th }}$ and $7^{\text {th }}$ graders instead PPTs, which would suggest that an early scientific learning addressing these issues enables better improvements. In our study, the participants had to deal with learning and/or remembering the scientific content knowledge together with the specific inquiry learning and NOSI as well as how to enact all these aspects in primary lessons and they experienced difficulties for integrating and applying all this knowledge in a semester. This assertion is in line with Stripple and Sommer (2015), who explored how teachers incorporate NOSI learning in chemistry lessons and found that they considered a low level of content knowledge as the ideal environment for learning about these aspects in order to reduce the cognitive load and to enable students to focus on NOSI and learning inquiry and science at the same time.

It needs to be acknowledged that this study presents some limitations. The qualitative nature of the study and the small number of participants $(\mathrm{N}=40)$ does not enable generalising the findings. Another aspect to highlight is the use of a particular instrument that combines NOSI aspects from different categorisations rather than using a standardised questionnaire, which makes difficult to compare our findings with other studies. Despite these constraints, our purpose was to examine the potential of our teaching intervention for promoting PSTS' NOSI adequate conceptions through qualitative analysis. Therefore, we consider that our methods are adequate to meet our goals.

Our findings suggest that NOSI needs to be explicitly addressed in science lessons together with inquiry performances in order to develop participants' informed views and performances of scientific inquiry. In addition, we agree with international recommendations such as Lederman et al.'s (2021), who point to a need of performing activities associated to real problems in order to promote the understanding and practice of scientific research in science lessons. Moreover, to do so, teachers need specific training on inquiry and NOSI, such as the module presented in this study. To conclude we consider that NOSI should be compulsory in scientific teaching programmes focusing on inquiry. 
Author notes: In memoriam of Doctor Naira Díaz-Moreno.

Author contributions: All authors have sufficiently contributed to the study, and agreed with the results and conclusions.

Funding: This research is funded by FEDER/Ministry of Science, Innovation and Universities-National Agency of Research/grant EDU2017-83915-R.

Acknowledgements: The authors would like to thank to the preservice teachers that take part in the study.

Declaration of interest: No conflict of interest is declared by authors.

\section{REFERENCES}

Acevedo, J. A. (2008). El estado actual de la naturaleza de la ciencia en la didáctica de las ciencias [The current state of the nature of science in science education]. Revista Eureka sobre Enseñanza y Divulgación de las Ciencias [Eureka Magazine on Teaching and Dissemination of Sciences], 5(2), 134-169. https://doi.org/10.25267/Rev_Eureka_ensen_div ulg_cienc.2008.v5.i2.02

Acevedo, J. A. (2009). Conocimiento didáctico del contenido para la enseñanza de la naturaleza de la ciencia (I): El marco teórico [Pedagogical content knowledge for teaching the nature of science (I): The theoretical framework]. Revista Eureka sobre Enseñanza y Divulgación de las Ciencias [Eureka Magazine on Teaching and Dissemination of Sciences], 6(1), 21-46. https://doi.org/10.25267/ Rev_Eureka_ensen_divulg_cienc.2009.v6.i1.02

Acevedo-Díaz, J. A., \& García-Carmona, A. (2016). Algo antiguo, algo nuevo, algo prestado. Tendencias sobre la naturaleza de la ciencia en la educación científica [Something old, something new, something borrowed. Trends on the nature of science in science education]. Revista Eureka sobre Enseñanza y Divulgación de las Ciencias [Eureka Magazine on Teaching and Dissemination of Sciences], 13(1), 3-19. https://doi.org/10.25267/ Rev_Eureka_ensen_divulg_cienc.2016.v13.i1.02

Acevedo-Díaz, J. A., García-Carmona, A., \& Aragón, M. A. (2017). Historia de la ciencia para enseñar naturaleza de la ciencia: Una estrategia en la formación inicial del profesorado de ciencia [History of science to teach nature of science: A strategy in the initial training of science teachers]. Educación Química [Chemical Education], 28, 140-146. https:/ / doi.org/10.1016/j.eq.2016.12.003

Allchin, D. (2011). Evaluating knowledge of the nature of (whole) science. Science Education, 95, 518-542. https:/ / doi.org/10.1002/sce.20432

Bell, R. L., Blair, L. M., Crawford, B. A., \& Lederman, N. G. (2003). Just do it? Impact of a science apprenticeship program on high school students' understandings of the nature of science and scientific inquiry. Journal of Research in Science Teaching, 40(5), 487-509. https://doi.org/10.1002/ tea. 10086
Berland, L., Schwartz, C. V., Krist, C., Kenyon, L., Lo, A. S., \& Reiser, B. J. (2016). Epistemologies in practice: Making scientific practices meaningful for students. Journal of Research in Science Teaching, 53(7), 1082-1112. https://doi.org/10.1002/tea. 21257

Capps, D. K., \& Crawford, B. A. (2013). Inquiry-based instruction and teaching about nature of science: Are they happening? Journal of Science Teacher Education, 24(3), 497-526. https:/ / doi.org/10.1007/ s10972-012-9314-Z

Crujeiras-Pérez, B., \& Puig, B. (2014). Trabajar la Naturaleza de la Ciencia en la formación inicial del profesorado planificando una investigación [Working on the Nature of Science in initial teacher training planning an investigation]. Educació Química, 17, 55-61.

Díaz Moreno, N., \& Crujeiras Pérez, B. (2016). Concepciones del profesorado en formación sobre naturaleza de la ciencia [Conceptions of preservice teachers about the nature of science]. Revista Internacional de Investigación e Innovación en didáctica de las humanidades y las ciencias, 3, 42-54.

Erduran, S., \& Dagher, Z. R. (2014). Reconceptualizing the nature of science for science education. Springer. https: / / doi.org/10.1007/978-94-017-9057-4

Erumit, B. A., Fouad, K. E., \& Akerson, V. L. (2019). How do learner-directed scientific investigations influence students' questioning and their nature of science conceptions? International Journal of Education in Mathematics, Science and Technology, 7(1), 20-31. https:/ / doi.org/0.18404/ijemst.509246

Escrivá-Colomar, I., \& Rivero-García, A. (2017). Progresión de las ideas de los futuros maestros sobre la construcción del conocimiento científico a través e mapas generados en una secuencia de actividades [Progression of future teachers' ideas about the construction of scientific knowledge through maps generated in a sequence of activities]. Revista Eureka sobre Enseñanza y Divulgación de las Ciencias [Eureka Magazine on Teaching and Dissemination of Sciences], 14(1), 199214. https:/ / doi.org/10.25267/Rev_Eureka_ensen _divulg_cienc.2017.v14.i1.15

García-Carmona, A., \& Acevedo-Díaz, J. A. (2018). The nature of scientific practice and science education. Science and Education, 27(5-6), 435-455. https:/ / doi.org/10.1007/s11191-018-9984-9

Guisasola, J., \& Morentin, M. (2007). Comprenden la naturaleza de la ciencia los futuros maestros y maestras de educación primaria? [Do future primary school teachers understand the nature of science?] Revista Electrónica de Enseñanza de las Ciencias [Electronic Journal of Science Teaching], 6(2), 246-262. 
Hamed, S., Rivero, A., \& Jiménez, J. (2017, September 58). Views about scientific inquiry (VASI): The case of Spain and Sweeden. In X Congreso Internacional sobre Investigación en Didáctica de las Ciencias [X International Congress on Research in Science Didactics]. Sevilla, Spain.

Julien, H. (2008). Content analysis. In L. M. Given (Ed.), The SAGE encyclopaedia of qualitative research methods (pp.120-121). SAGE. https://doi.org/10.4135/ 9781412963909.n329

Kampourakis, K. (2016). The "general aspects" conceptualization as a pragmatic and effective means to introducing students to nature of science. Journal of Research in Science Teaching, 53(5), 667-682. https://doi.org/10.1002/tea.21305

Kelly, G. J. (2008). Inquiry, activity, and epistemic practice. In R. Duschl, \& R. Grandy (Eds.), Teaching scientific inquiry: Recommendations for research and implementation (pp. 99-117). Sense Publishing. https://doi.org/10.1163/9789460911453_009

Leblebicioglu, G., Metin, D., Capkinoglu, E., Cetin, P. S., Dogan, E. E., \& Schwartz, R. (2017). Changes in students' views about nature of scientific inquiry at a science camp. Science and Education, 26, 889-917. https://doi.org/10.1007/s11191-017-9941-z

Lederman, J. S., Lederman, N. G., Bartos, S. A., Bartels, S. L., Meyer, A. A., \& Schwartz, R. S. (2014). Meaningful assessment of learners' understandings about scientific inquiry: The views about scientific inquiry (VASI) questionnaire. Journal of Research in Science Teaching, 51(1), 65-83. https://doi.org/ 10.1002 / tea. 21125

Lederman, J., S., Lederman, N. G., Bartels, S., Jiménez, J., Acosta, K., Akubo, M., Aly, S., Andrade, M. A. B. S., Atanasova, M., Blanquet, E., Blonder, R., Brown, P., Cardoso, R., Castillo-Urueta, P., Chaipidech, P., Concannon, J., Dogan, O. K., El-Deghaidy, H., Elzorkani, A., ... Wishart, J. (2021). International collaborative follow-up investigation of graduating high school students' understandings of the nature of scientific inquiry: Is progress being made? International Journal of Science Education, 43(7), 9911016. https://doi.org/10.1080/09500693.2021. 1894500

Lederman, N. G. (1992). Students' and teachers' conceptions of the nature of science: A review of the research. Journal of Research in Science Teaching, 29(4), 331-359. https:/ / doi.org/10.1002/tea.366029 0404

Lederman, N. G. (1999). Teachers' understanding of the nature of science. Factors that facilitate or impede the relationship. Journal of Research in Science Teaching, 36(8), 916-929. https://doi.org/10.1002/ (SICI)1098-2736(199910)36:8<916::AID-TEA2> 3.0.CO;2-A
Lederman, N. G., \& Lederman, J. S. (2014). Research on teaching and learning of nature of science. In N. G. Lederman, \& S. K. Abell (Eds.), Handbook of research on science education (pp. 600-620). Routledge. https: / / doi.org/10.4324/9780203097267-41

Lederman, N. G., Lederman, J. S., \& Antink, A. (2013). Nature of science and scientific inquiry as contexts for the learning of science and achievement of scientific literacy. International Journal of Education in Mathematics, Science and Technology, 1(3), 138-147.

Mellado Jiménez, V. (1996). Concepciones y prácticas de aula de profesores de ciencias en formación inicial de primaria y secundaria [Conceptions and classroom practices of science teachers in initial training of primary and secondary]. Enseñanza de las Ciencias [Science Education], 14(3), 289-302. https:/ / doi.org/10.5565/rev/ensciencias.4205

Mesci, G., Schwartz, R. S., \& Pleasants, B. A. (2020). Enabling factors of preservice science teachers' pedagogical content knowledge for nature of science and nature of scientific inquiry. Science and Education, 29, 263-297. https://doi.org/10.1007/ s11191-019-00090-W

National Research Council (NRC). (2000). Inquiry and the national science education standards: A guide for teaching and learning. National Academies Press.

Nehring, A. (2018). Naïve and informed views on the nature of scientific inquiry in large-scale assessments: Two sides of the same coin or different currencies? Journal of Research in Science Teaching, 57, 510-535. https://doi.org/10.1002/tea.21598

Organisation for Economic and Cooperative Development (OECD). (2016). PISA 2015 assessment and analytical framework: Science, reading, mathematic and financial literacy. OECD Publishing.

Osborne, J. (2014). Scientific practices and inquiry in the science classroom. In N. G. Lederman, \& S. K. Abell (Eds.), Handbook of research on science education (pp. 579-599). Routledge.

Osborne, J., Collins, S., Ratcliffe, M., Millar, R., \& Duschl, R. (2003). What "ideas-about-science" should be taught in school science: A Delphi study of the expert community. Journal of Research in Science Teaching, 40(7), 692-720. https://doi.org/10.1002/ tea.10105

Ryder, J., \& Leach, J. (2008). Teaching about the epistemology of science in upper secondary schools: An analysis of teachers' classroom talk. Science and Education, 17, 289-315. https:/ / doi.org/ 10.1007/s11191-006-9007-0

Sandoval, W. A., \& Morrison, K. (2003). High school students' ideas about theories and theory change after a biological inquiry unit. Journal of Research in Science Teaching, 40(4), 369-392. https://doi.org/ 10.1002/tea.10081 
Schreirer, M. (2012). Qualitative content analysis in practice. SAGE.

Schwartz, R. S. (2004). Epistemological views in authentic science practice: A cross-discipline study of scientists' views of nature of science and scientific inquiry [Doctoral dissertation, Oregon State University].

Schwartz, R. S., \& Lederman, N. G, (2008). What scientists say: Scientists' views of nature of science and relation to science context. International Journal of Science Education, 30(6), 727-771. https:/ / doi.org/10.1080/09500690701225801

Schwartz, R. S., Lederman, N. G., \& Lederman, J. S. (2008, March 30-April 2). An instrument to assess views of scientific inquiry: The VOSI questionnaire. In National Association for Research in Science Teaching. Baltimore, USA.

Schwartz, R., Lederman, N., \& Abd-El-Khalick, F. (2012). A series of misrepresentations: A response to Allchin's whole approach to assessing nature of science understandings. Science Education, 96(4), 685-692. https:/ / doi.org/10.1002/sce.21013

Senler, B. (2015). Middle school students' views of scientific inquiry: An international comparative study. Science Education International, 26(2), 166-179.

Strippel, C. G., \& Sommer, K. (2015). Teaching nature of scientific inquiry in chemistry: How do German chemistry teachers use labwork to teach NOSI? International Journal of Science Education, 37(18), 2965-2986. https:/ / doi.org/10.1080/09500693.2015 .1119330

Vázquez Alonso, A., García-Carmona, A., ManasseroMas, M. A., \& Bennàsar-Roig, A. (2014). Spanish students' conceptions about NOS and STS issues: A diagnostic study. EURASIA Journal of Mathematics Science and Technology Education, 10(1), 33-45. https:/ / doi.org/10.12973/eurasia.2014.1013a

Vázquez, A., Acevedo, J. A., \& Manassero, M. A. (2004). Consensos sobre la naturaleza de la ciencia: Evidencias e implicaciones para su enseñanza [Consensus on the nature of science: Evidence and implications for its teaching]. Revista Iberoamericana de Educación [Ibero-American Journal of Education], 34(1). https:/ / doi.org/10.35362/rie3412895

Vázquez-Alonso, A., \& Manassero-Mas, M. A. (2016). El efecto de un programa de formación para profesores sobre sus concepciones de naturaleza de la ciencia y tecnología [The effect of a training program for teachers on their conceptions of the nature of science and technology]. Revista Electrónica Interuniversitaria de Formación de Profesorado [Interuniversity Electronic Journal of Teacher Training], 19(2), 223-239

Vhurumuku, E., \& Mokeleche, M. (2009). The nature of science and indigenous knowledge systems in South Africa, 2000-2007: A critical review of the research in science education. African Journal of Research in Mathematics, Science and Technology Education, 13, 96-114. https://doi.org/10.1080/ 10288457.2009.10740664

Yang, I., Park, S., Shin, J., \& Lim, S. (2017). Exploring Korean middle school students' view about scientific inquiry. EURASIA Journal of Mathematics Science and Technology Education, 13(7), 3935-3958. https:/ / doi.org/10.12973/eurasia.2017.00765a 


\section{APPENDIX A}

Survey Used in the Pre- \& Post-Test for Examining Participants' Epistemic Knowledge

1. Considering the following diagrams:

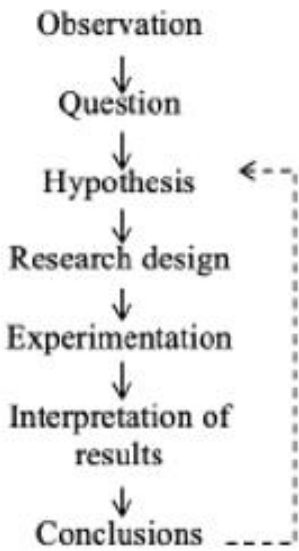

a

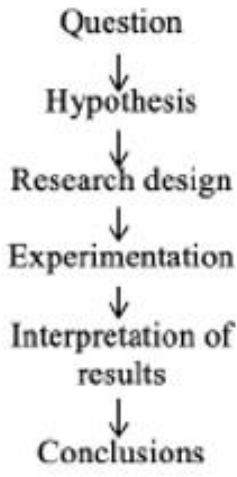

b

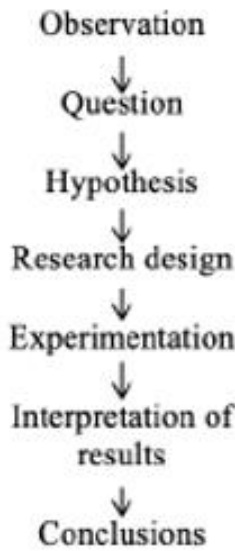

c

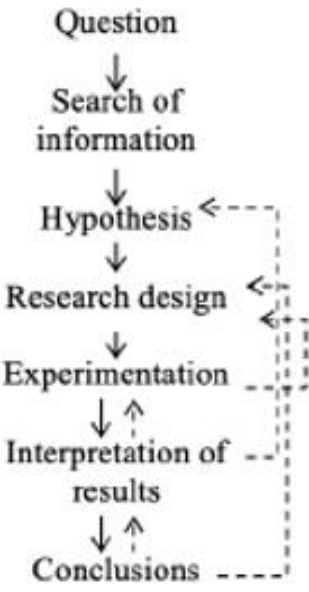

d

Choose which of them do you think it would be the best for carrying out a scientific investigation and explain why

2. If you had to select an adequate and reliable procedure to identify microplastics in beach sand, which of the following would you choose? Justify your answer

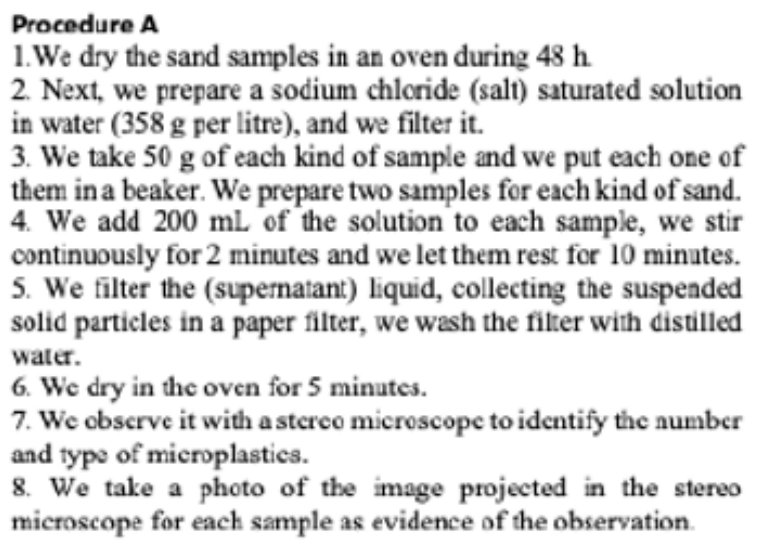

\section{Procedure B}

1. We dry the sand samples in an oven during $48 \mathrm{~h}$.

2. We prepare a sodium chloride (salt) saturated solution in water (358 g per litre), and we filier it.

3. We take $50 \mathrm{~g}$ of each kind of sample and we put each one of them in a beaker.

4. We add $200 \mathrm{~mL}$ of the solution to each sample, we stir and let them rest for some minutes.

5. We fiiter the (supematant) liquid, and we collect the suspended solid particles in a paper filter.

6. We wash the filter.

7. We observe it with a sterco mieroscope to identify the number and type of microplastics.

3. A group of students want to find out what is the best material to build a race track for toy cars. To do so, they investigate three types of materials: plastic, wood and cork. They conduct an experiment by sliding a toy car through an inclined plane that they cover each time with one of the materials to be investigated. As a result, they get that the cork is the material that allows the car to move faster.

Do you think that the findings they obtained are reliable? Justify your answer 
4. A group of students obtained the following data in an investigation about the effect of temperature on the dissolution rate of cocoa in water:

\begin{tabular}{|l|l|l|l|}
\hline T(º' & \multicolumn{3}{|c|}{ t(s) } \\
\hline 20 & 123 & 100 & 121 \\
\hline 40 & 100 & 99 & 100 \\
\hline 65 & 60 & 60 & 60 \\
\hline 100 & 32 & 30 & 31 \\
\hline
\end{tabular}

Which of the following conclusions would be the most scientifically appropriate?

\section{Justify your choice}

Conclusion a: temperature directly influences the rate of cocoa dissolution Conclusion b: the rate of cocoa dissolution increases as we raise the temperature Conclusion c: the rate of cocoa dissolution decreases as we raise the temperature Conclusion d: temperature directly influences the dissolution rate of cocoa because as we increase it the dissolution rate also increases, as at $100^{\circ} \mathrm{C}$ degrees cocoa takes less time to dissolve than at $20^{\circ} \mathrm{C}$

https://www.ejmste.com 